\title{
Effect of Wind Pressure on Glass Facade
}

\author{
Trisha Shetty ${ }^{1}$, Darshan Verma ${ }^{2}$, Pushpraj Singh ${ }^{3}$, Rakesh Verma ${ }^{4}$, \\ Prof. Dhaval Bhandari ${ }^{5}$, Prof. Naveen Hanchinahal ${ }^{6}$ \\ 1,2,3,4 (UG Students), ${ }^{5,6}$ Assistant Professor, Department of Civil Engineering, St John College of Engineering \& \\ Management, Palghar
}

DOI: 10.46335/IJIES.2020.5.7.6

\begin{abstract}
Glass facade has gradually become main external wall material in high-rise buildings due to its multi functionalization and diversification. Nevertheless, glass is relatively fragile and prone to fracture when subjected to the coupling effect of fire and external wind load that inevitably significant influences the mechanical property of glass facades in high-rise buildings. Facades are the first aesthetical feature of a building that distinguishes one building from another. Its distinctive appearance is often the subject of controversial debate. Nowadays, Unitized glass facade system is usually used for new high-rise buildings; it becomes a major investment in both construction and long-term success of the building. Compared to reinforced concrete structure, unitized curtain wall is new technology in the construction industry. This dissertation will focus on the design and analysis of effect of wind pressure on glass façade for high-rise building. The wind loading calculations have a considerable have an effect on the sizing of glass facades elements; however there are substantial differences between wind loading codes in different countries. There are also significant differences between the wind loading data obtained from these codes. This document therefore reviews the nature and effects of wind loading on facades and compares the current simplified methods for predicting wind Loading provided in recent codes of practice. The main objective of this study to compare the performance of the façade based on Displacement. Analysis and design $G+30$ building using STADD Pro. Software The design involves load calculations manually and analyzing the whole structure by STAAD Pro.
\end{abstract}

Keywords-Glass Facade, Diversification, Wind loading, STADD Pro.

\section{I- INTRODUCTION}

$\mathbf{S}_{\mathrm{r}}$ and building industry. Glass is a material commonly used in facade systems. It is a material known for millennia and has been used in buildings for centuries. Nowadays it is being used as a structural material rather than a transparent infill within a supporting frame. The changing approach to the use of glass has been made possible by the improved quality of glass, development of the float glass and thermal strengthening (tempering) process and the availability of analysis tools.

For the design of facade systems in India, ASTM / Euro Codes are normally followed as Indian Codes do not address such information. This necessitates more study on the structural performance of glass panels for Indian conditions. In the proposed study, the glass panels with different end conditions, at different loadings and for different aspect ratio will be analysed which will help the designers. This study is the state-of-art discussing the types of glasses in facades, their applications, functional and strength requirements in tall buildings.

Wind induced pressure is a major design consideration for determining the glass thickness and glass selection in façades.. Furthermore the use of emerging computational techniques for determining the wind loads on façades, 
such as Computational Fluid Dynamics (CFD), is relatively untested.

The first part of this study consists of a brief introduction to five international wind loading codes of practice along with an introduction to wind tunnel testing and computational wind engineering and their application in the design of glazed façades. This is followed by a series of wind load predictions for a notional test case using both existing wind loading codes and CFD analysis. Finally the load predictions are compared to the results from a number of wind tunnel studies and full- scale measurements that were performed by others on an identical notional test case.

The following are the types of glasses commonly used in building industry as facades-

1) Annealed Glass

2) Tempered or Toughened Glass

3) Heat Strengthened Glass;

4) Reflective Glass and Laminated Glass.

\section{II- OBJECTIVES}

1. To study the design of glass façade depending on the type and requirement of the grid and to evaluate different combination grid holding glass for comparing the façade as whole.

2. To compare the performance of the façade based on displacement.

3. To study the effect of wind pressure on façade

\section{III- METHODOLOGY}

i. To collect and study the past literature glass facade.

ii. Identifying of Basic model and typical structure and compare the performance of the façade based on displacement.

iii. Validation of Software for the selected software.

iv. Comparison of Software analysis with Manual analysis.

v. Interpretation of Result for combination of glass façade.

\section{IV-RESULTS}

1) Analytical Results Different Glass Facade of $3 X 5$ Panels:

a. Reactions
In figures 1.1, 1.2, 1.3, the Graph showing analytical results for wind reaction (FX,FY,FZ) on glass facade panels by using STADD PRO software. Graph including in wind reactions of three model such as facade 1 , facade 2 , facade 3 which is expressed in $\mathrm{KN}$.

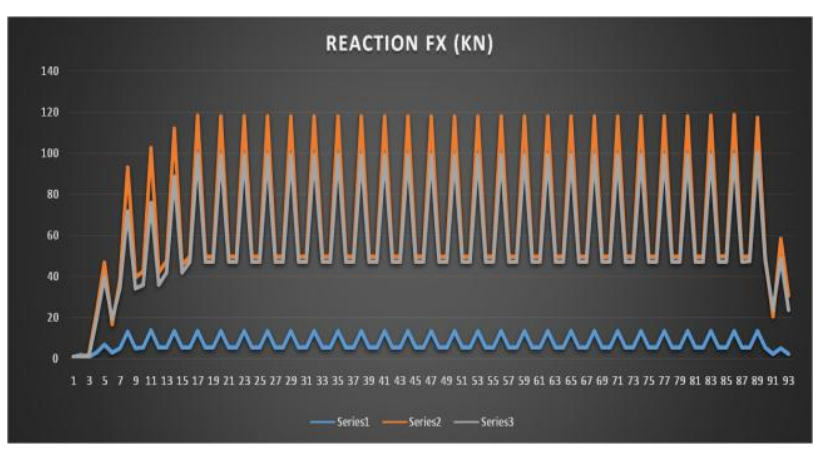

Fig.1.1. Reaction (FX) for Glass Facade Panel 3X5 m

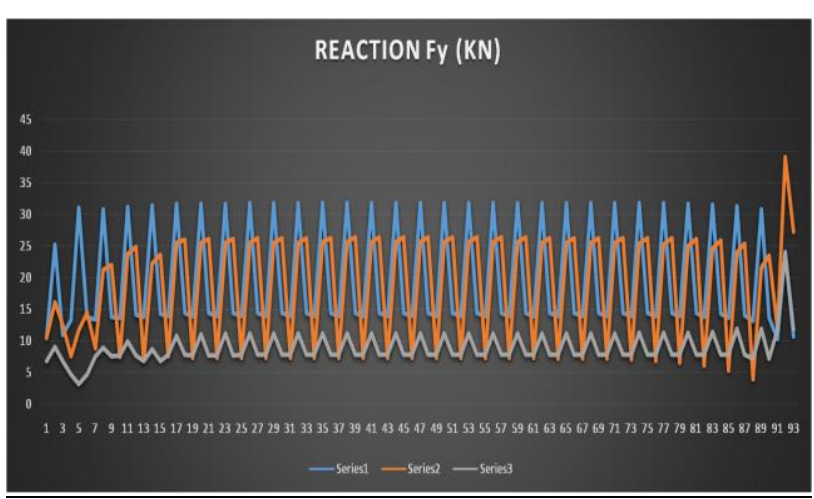

Fig.1.2. Reaction (FY) for Glass Facade Panel 3X5 m

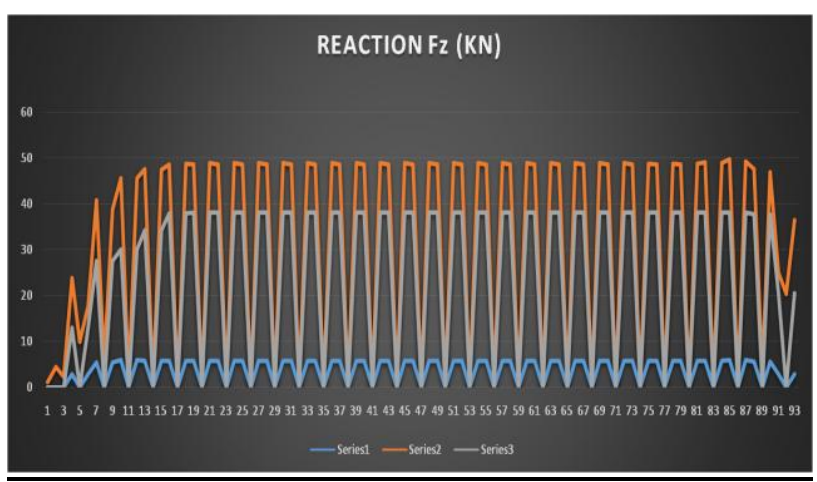

Fig.1.3. Reaction (FZ) for Glass Facade Panel 3X5 m

\section{b. Stresses}

In the fig.1.4. graph showing analytical results for compressive stresses on glass facade panels by using STADD PRO software. graph included in wind stresses of three models such as facade 1 , facade 2 , facade 3 which is expressed in $\mathrm{KN} / \mathrm{mm}$. 


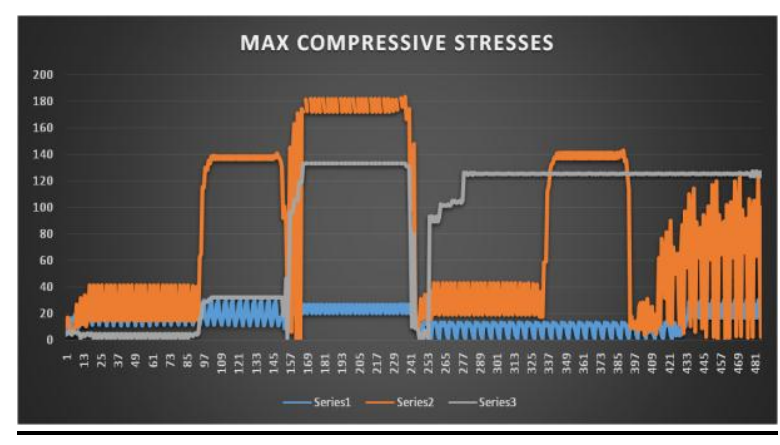

Fig.1.4. Maximum Compressive Stresses for Glass Facade Panel 3X5 m.

In the fig.1.5. graph showing analytical results for tensile stresses on glass facade panels by using STADD PRO software. Graph included in wind stresses of three models such as facade 1 , facade 2 , facade 3 which is expressed in $\mathrm{KN}$.

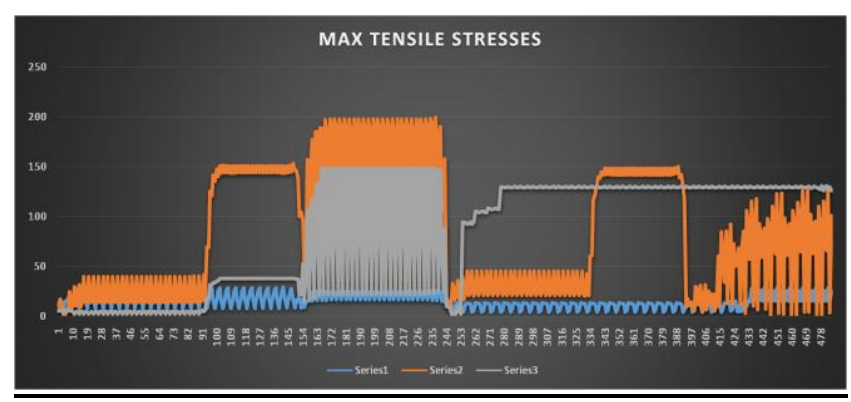

Fig.1.5. Maximum Tensile Stresses for Glass Facade Panel 3X5 m.

\section{c. Relative Displacements (z)}

In the fig.1.6 Graph showing analytical results for maximum displacement on glass facade panels by using STADD PRO software. Graph included in displacement of three models such as facade 1 , facade 2 , facade 3 which is expressed in $\mathrm{mm}$.

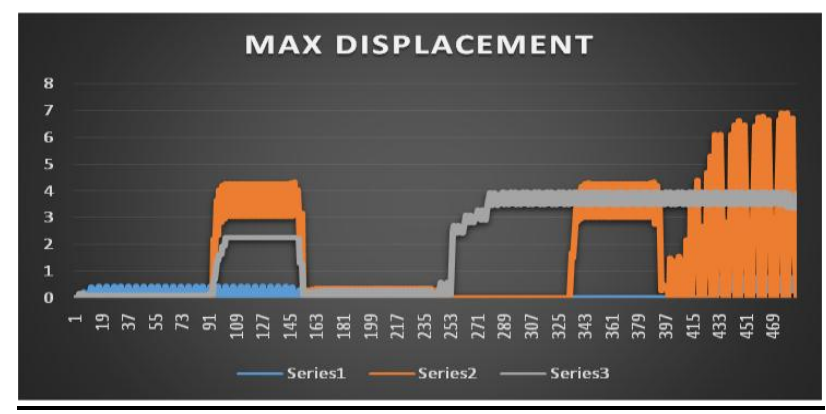

Fig.1.6. Maximum Relative Displacement for Glass Facade Panel 3X5.

\section{d. Resultant}

In fig.1.7. the Graph showing analytical results for tensile stresses on glass facade panels by using STADD PRO software. Graph included in resultant of three models such as façade.

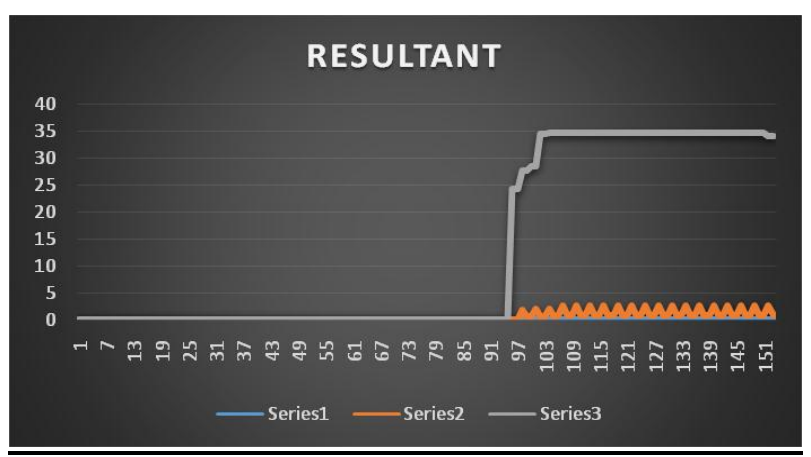

Fig.1.7. Resultants for Glass Facade Panel 3X5m

\section{2) Analytical Results Different Glass Facade of 6X5} Panels:

\section{a. Reactions}

In figures.2.1, 2.2, 2.3 the Graph showing analytical results for wind reaction (FX. FY, FZ) on glass facade panels by using STADD PRO software. Graph including in wind reactions of three model such as facade 1 , facade 2 , facade 3 which is expressed in $\mathrm{KN}$.

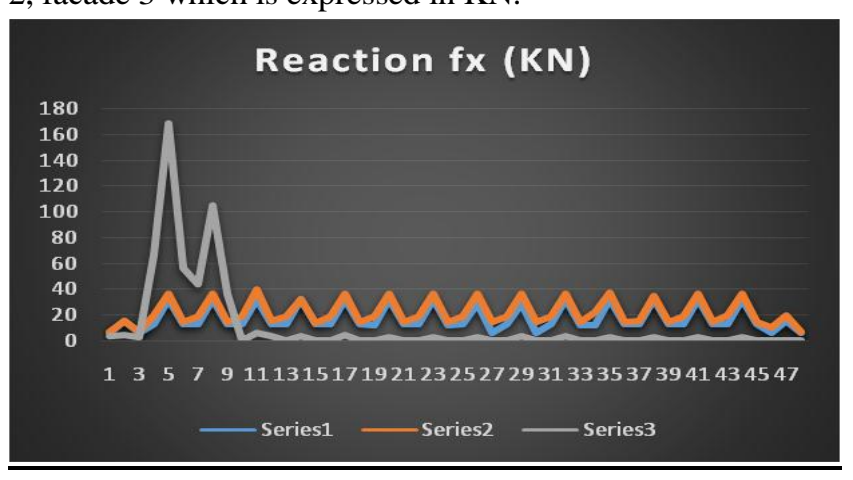

Fig.2.1. Reaction (FX) for Glass Facade Panel 6X5 m.

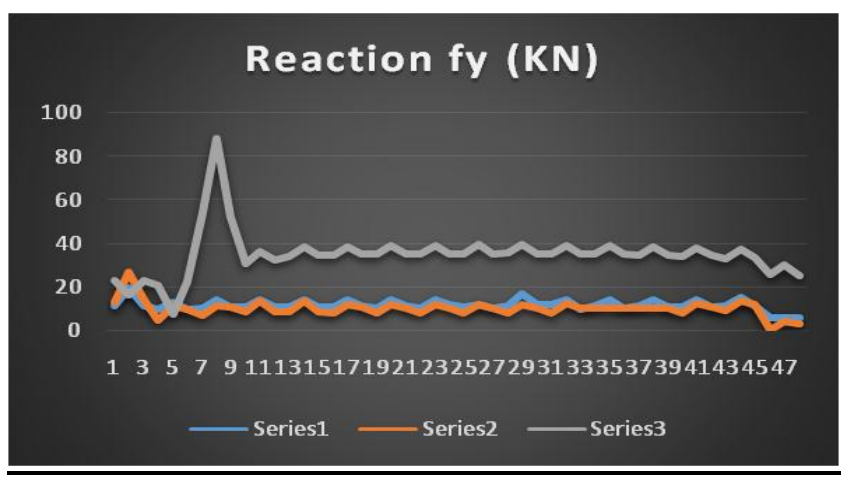

Fig.2.2. Reaction (FY) for Glass Facade Panel 6X5 m. 


\section{$w w w . i j i e s . n e t$}

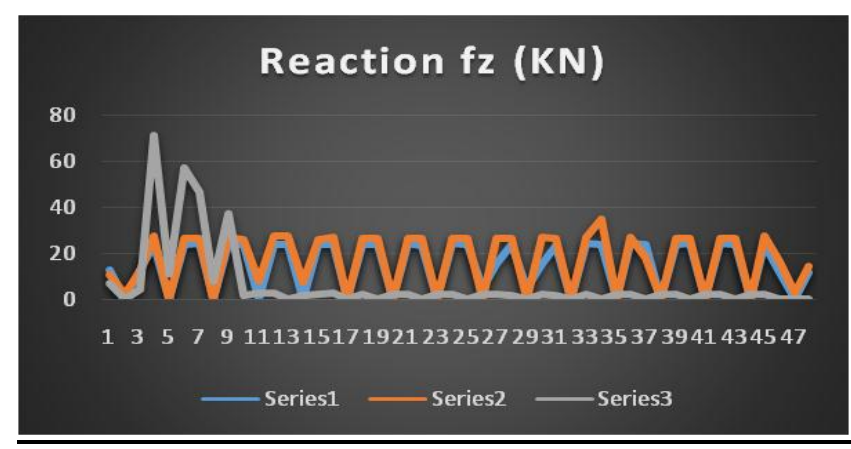

Fig.2.3. Reaction (FZ) for Glass Facade Panel 6X5 m.

\section{b. Stresses}

In fig.2.4. the graph showing analytical results for compressive stresses on glass facade panels by using STADD PRO software. graph included in wind stresses of three models such as facade 1 , facade 2 , facade 3 which is expressed in $\mathrm{KN} / \mathrm{mm}$.

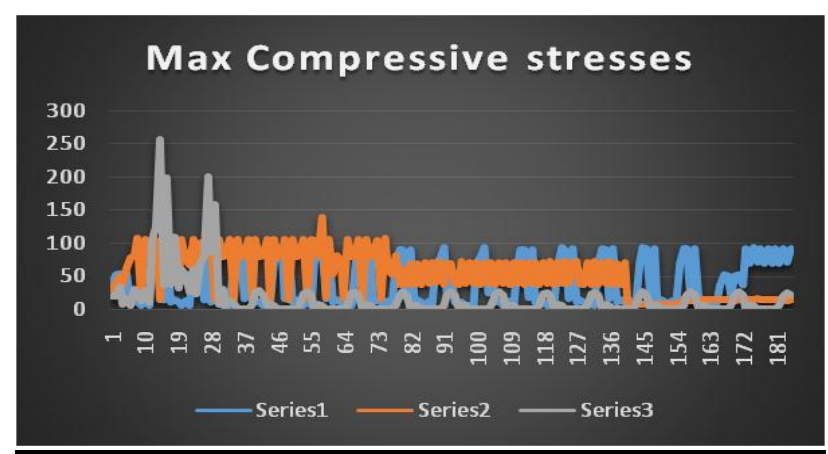

Fig.2.4. Maximum Compressive Stresses for Glass Facade Panel 6X5 m.

In the fig.2.5. graph showing analytical results for tensile stresses on glass facade panels by using STADD PRO software. Graph included in wind stresses of three models such as facade 1 , facade 2 , facade 3 which is expressed in KN.

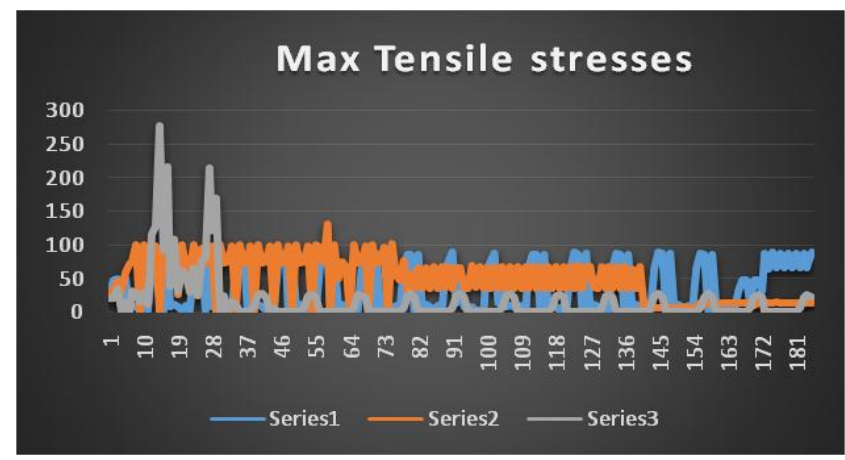

Fig.2.5. Maximum Tensile Stresses for Glass Facade Panel 6X5 m.

\section{c. Relative Displacements (z)}

In the fig.2.6 Graph showing analytical results for maximum displacement on glass facade panels by using STADD PRO software. Graph included in displacement of three models such as facade 1 , facade 2 , facade 3 which is expressed in $\mathrm{mm}$.

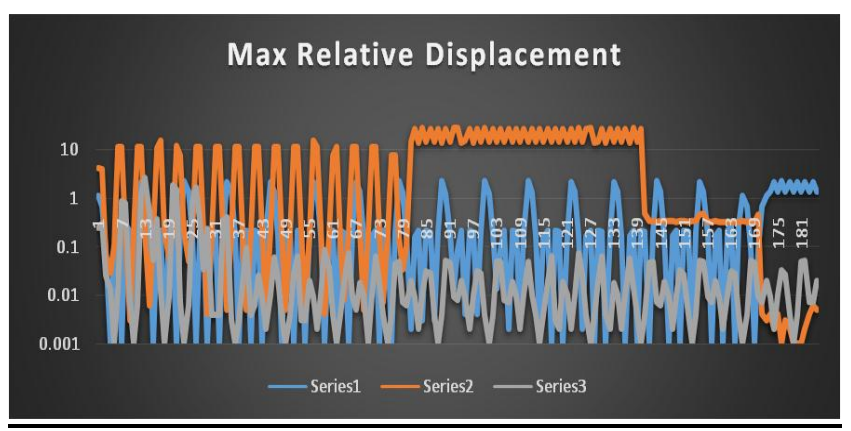

Fig.2,6. Maximum Relative Displacement for Glass Facade Panel 6X5.

\section{d. Resultant}

In fig.2.7. the Graph showing analytical results for tensile stresses on glass facade panels by using STADD PRO software. Graph included in resultant of three models such as façade.

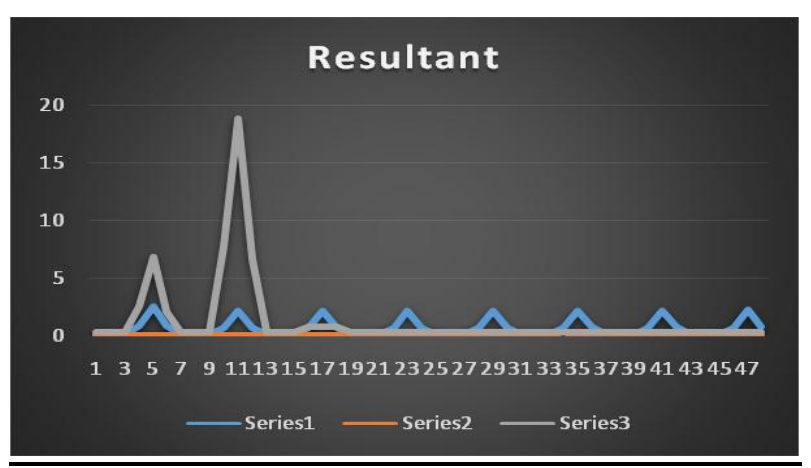

Fig.2.7. Resultants for Glass Facade Panel 6X5m

\section{III-CONCLUSIONS}

This study has reviewed the nature and effects of wind loading on façades and qualitatively compared the recent international codes of practice to computational wind engineering. A basic quantitative comparison was also achieved by determining the external pressure coefficients on a notional $3 \times 5 \mathrm{~m}$ and $6 \times 5$ panels analysis. The results from this analysis were compared to those obtained from international codes of practises.

In this glass facade $3 \times 5 \mathrm{~m}$ panels are following conclusion are listed below:

\section{- Reaction}


As per the Reaction results, G2 is grabbing more force as compare to G1\&G3 So hence there are more chances of failure of $\mathrm{G} 2$ façade as compare to $\mathrm{G} 1 \& \mathrm{G} 2$. G3 is performing well as compare to $\mathrm{G} 2$.

\section{- Stresses}

As per the Stresses result, G3 Stresses are uniform at some points and there are no much fluctuations and G3 façade is taking the same reaction load but the stresses are uniform at some point .So G3 is performing well as compare toG1\&G2.

\section{- Displacement}

As per the Displacement result,G2 has much stresses but the displacement is too more due to which there are chance of failure .Hence G3 is performing well as compare to G2 .(Elastic Behaviour )

\section{- Resultant}

As per the resultant result,G3 is performing max in resultant and there are some fluctuations.\& G1and $\mathrm{G} 2$ is much stable in resultant. So here G1,G2and G3 performance is much same.

In this glass facade $6 \times 5 \mathrm{~m}$ panels are following conclusion are listed below:

\section{- Reaction}

$>$ As per the Reaction results, G3 is grabbing more force as compare to G1\&G2 So hence there are more chance's of failure of G3 façade as compare to $\mathrm{G} 1 \& \mathrm{G} 2$. G2 is performing well as compare to G1.

\section{- Stresses}

$>$ As per the Stresses result, G2 Stresses are uniform throughout the result and there are no much fluctuations and G2 façade is taking the same reaction load but the stresses are uniform .So G2 is performing well as compare toG1\&G3

\section{- Displacement}

$>$ As per the Displacement result,G1\&G3 has much stresses

$>$ but the displacement is too low due to which they show a

$>$ brittle behaviour, Hence G2 is performing well as

$>$ compare to G1\&G2 .(Elastic Behaviour )

\section{- Resultant}

$>$ As per the resultant result,G1\&G3 is performing max in resultant due to which failure chance's are more and Hence G2 resultant is stable as compare to G3 so the performance wise G2 is better than G1\&G3.

\section{VI - FUTURE SCOPE}

$>$ The Finite Element Analysis of Glass Stresses Generation and Transfer of load to the Glass Façade.

Comparison between in build structural element providing façade and temporary façade.(External frames)

\section{REFERENCES}

[1] Dr. Mauro Overnd, Kennethzammit, "Wind Loading On Cladding And Glazed Facades, International Symposium On The Application Of Architectural Glass, ISAAG 2006

[2] Filipe Amarante Dos Santos, Pedro F. Gon Calves, et. al., "Smart Glass Fa, Cade Subjected To Wind Loadings", Research Gate, 2014.

[3] Mehdi Shahrestani A, Runming Yao, et.al., "Experimental And Numerical Studies To Assess The Energy Performance Of Naturally Ventilated $P V$ Façade Systems", Solar Energy, Vol. 147, Pp. 3751, 2017.

[4] Rao G.S. K. Rajasekhar, "Structural Design Of Toughened Glass Facade Usingeuro Code”, IJRET: International Journal of Research In Engineering And Technology, Volume: 04 Special Issue: 13, 2015

[5] Thanyalak Srisamranrungruang, Kyosuke Hiyam, "Balancing of natural ventilation, daylight, thermal effect for a building with double-skin perforated facade (DSPF)", Energy \& Buildings, 2020

[6] Y.M. Abdlebasset, E.Y. Sayed-Ahmed, "High-Rise Buildings with Transfer Floors: Linear Versus Nonlinear Seismic Analysis", Electronic Journal of Structural Engineering, Vol. 16 No 1, 2016.

[7] IS 875 - Bureau Of Indian Standards Manak Bhavan, 9 Bahadur Shah Zafar Marg, New Delhi110002. 
International Journal of Innovations in Engineering and Science, Vol 5, No.7, 2020

\section{$w w w . i j i e s . n e t$}

[8] Is 456 - Bureau Of Indian Standards Manak Bhavan, 9 Bahadur Shah Zafar Marg New Delhi 110002

[9] Is 1893-2016 - Bureau Of Indian Standards Manak Bhavan, 9 Bahadur Shah Zafar Marg, New Delhi 110002.

[10] Is 1893-2016 - Bureau Of Indian Standards Manak Bhavan, 9 Bahadur Shah Zafar Marg, New Delhi 110002.

[11] Is 875 (Part 2): Code Of Practice For Design Loads (Other Than Earthquake) For Buildings And Structures. Part 2: Imposed Loads (Second Revision) (1987) 